\section{The Harveian Oration}

ON

\section{THE DEBT OF PREVENTIVE MEDICINE TO HARVEY AND THE COLLEGE OF PHYSICIANS}

Delivered before the Royal College of Physicians OF LONDON ON OCTOBER 18Th, 1932

BY

Sir GEORGE NEWMAN, K.C.B., M.D., D.C.L., LL.D., F.R.C.P.

CHIEF MEDICAL OFFICER OF THE MINISTRY OF HEALTiH

I am indeed very sensible, Sir, of the honour which you confer upon me in the imposition of this task, and I venture to express my grateful appreciation by offering for your consideration a brief commemoration of some of the benefactors of the College who have advanced the study and application of the preventive principles of Medicine, and of whom Harvey was the forerunner.

The facts of Harvey's life have often been recited within these walls, and are well known to you. His fame rests upon two achievements. He rendered the College of Physicians manifold services for half a century, and left it precious legacies and benefits. And by his discovery of the circulation of the blood, which Sir Thomas Browne preferred to the discovery of America, he became the founder of modern physiology. He it was who opened wide for the science of Médicine the gates of the Renaissance and revealed, like Copernicus, a new orientation of human thought. The discovery itself was twofold: that the blood throughout the living body circulated from the heart through the arteries and back to the heart again through the veins, and that this movement was propelled by the contraction of the heart. The establishment of these two simple facts ended notions, theories, and doctrines which had endured for 1,500 years.

Harvey's demonstration of the mechanism of the circulation of the blood was pregnant with vast consequences, loaded with fate, something more than an interpretation of the special function of the heart and blood vessels, more than the explanation of a mechanical act. For in the first place, following Aristotelian principles which he learned at Padua (which was more Aristotelian than the Platonic Academy at Florence attended by Linacre), Harvey arrived at his conclusion, not from books nor yet by logical deduction of known facts, but by direct observation and experiment. In his little book, one of the most wonderful little books in the history of man, lee sets out, step by step, the mechanical course of events in the cardiac cycle, illustrated by his own convincing tests and experiments. Thus he applied the scientific methods of Aristotle and Roger Bacon as an example of the means of discovering the secrets of Nature. As a Vesalian anatomist he studied the anatomical morphology of the blood system in both man and animals; as a Galenic disciple he conceived of the function of the structures he found, and devised experiments, by vivisection or otherwiss, for proving the validity of his interpretations; and he was one of the first to use physical measurement in biological inquiry.

And in the second place, Harvey is never in any doubt that an understanding of the circulation provides the only basis for the intelligent study of the function of the blood itself and of the physical nature of man, of which he claims the heart as sovereign. So long as the blood contained demons and spirits, was dual in character, and was static or tidal, and so long as the heart was a mixing-tank and heat generator rather than the propeller of a circulating fluid, there could be no new physiology. Thus, whilst he neither foresaw nor formulated the sub- sequent research in physiological problems, he led men to expect an abundant harvest from his seed-sowing. $\mathrm{He}$ also tells us that as a circulating blood carries nutriment so it carries infection and contagion, the poison of wounds, the virus of serpent bite, the infection of rabies of the dog, of syphilis, and of ague.

\section{The New Physiology}

Here, therefore, was the opening of a new epoch Men's minds were turned intensively to problems concerning the nature of man and to fresh methods of grappling with such problems. Is it surprising that new and emergent discoveries were manifold and of vital concern? They were not designed, or even foreseen, by Harvey, yet it was by Harvey's method that they were attained, and a circulating blood was lord of their event. . .

From these discoveries I turn to mention some of their applications in Preventive Medicine. The organized attempt to prevent disease began in England in the fourteenth century, when the nation was faced with the disaster of the Black Death, which reduced the population from four millions to two millions in a single year. From that dark day to the present there has been steady, and in recent years rapid, advance. From the sixteenth century the State itself took a hand in the business, and in our own time has secured the co-operation of the private practitioner, the research investigator, and the public medical officer. Their joint achievements have distinguished the last hundred years beyond other secular periods. I suppose that in no previous epoch in the history of mankind has there been such growth of the conception of preventive medicine and the practice of its art. It has saved millions of lives from premature death or crippling disease ; it has extended the expectation of life for every infant born ; it has, in Rudyard Kipling's phrase, " smote for us a pathway to the ends of all the earth," peopling whole tracts of the world which have formerly been decimated or deserted. In doing these things it has become a primary factor in the destiny of nations and in the future of man's life.

It is difficult to make a selection of illustrations, from what Dryden would have called " God's plenty," to prove this growth of knowledge or its applications, because of their manifold and varied character. But I will offer for your consideration three examples, and each of them shall be a descendant of the achievement of the immortal Harvey.

\section{The Physiological Balance as a Conservation} of Health

No one can consider the formidable and varied advances of modern physiology without wondering whether it is possible to weave them into a synthetic " grand purpose," as Borelli foresaw it. Apart from his specific discoveries this is what Claude Bernard did, and it was perhaps his greatest service to physiology.

"Animals have really two environments," he said, " an external environment in which the organism is situated, and an internal environment in which the tissue elements live. ... All the vital mechanisms of the body, varied as they are, have only one object, that of preserving constant the conditions of life in the internal environment."

This is the synthetic principle of Bernard, that all the vital functions of the body establish jointly a constant and stable internal environment for the organism which lives its life amid a variable external environment. Bernard was led to his conclusion by the constancy of the proportion of sugar in the blood as regulated by the liver, but in the last half-century we have learned of the relative constancy of the alkalinity and content of the blood (even in transfusion), of the process of respiration, of body temperature, of the nervous integration and regulation of the body, and of the control of the body 
by the circulation in the blood of the endocrine secretions. Wherever we turn we find evidences of this internal constancy, maintained by respiration, circulation, the course of digestion and nutrition, the activities of the liver and kidney, the secretions of the ductless glands, and the total metabolism of the normal body. We must be reserved in attempting to assess the findings of physio$\operatorname{logy}$, to say what is great and what is small, but we shall be safe in accepting provisionally this supreme synthetic interpretation as among its highest gifts.

The further Claude Bernard reflected upon his deduction the more convinced he became both of its validity and of its practical application. He saw indeed in his day that health and capacity depend upon this physiological balance of the constant internal environment, surviving and moving in a variable external environment. $\mathrm{He}$ wanted men to understand it, to regard it, and to live by it. We now see in our day that the mastery is being attained, in rationale and in practice. In a word, we are beginning to apprehend the physiological life as the basis of health and as the foundation of Preventive Medicine. To have learned that fact is the beginning of wisdom. Claude Bernard, like Harvey and Hippocrates before him, saw that the physiological life, Nature herself, is the healer of disease and the protection against its invasion.

This conception was first put into practice in the fifth century B.c. in the Aesculapian temples, the sanatoriums of the ancient world; it was carried forward by the gymnastics of the Greeks, by the hygienic vision and education of Hellenism, by the substitution of natural aetiology for the supernatural daemonic magic and medicine of the East; it inspired the sanitation of the Roman Empire, and there, in the writings of Celsus, Pliny, and Cicero, it lay embalmed for centuries. The conservation of health in physiological balance revived in the Renaissance, and was carried from Florence to Padua, and thus to Leyden and England. We may find it in the letters of Erasmus, in More's Utopia, in Linacre's translation of Galen's Preservation of Health, scattered through Shakespeare's plays, in the writings of Sir Thomas Browne and Lord Bacon, in Sydenham's letters, in the great work on hygiene of Peter Frank the Bavarian - everywhere for the rich and scholarly. Yet it still had to be given to the great mass of the people.

It was given them by Lind in relation to nutrition; by William Cadogan for mothers and children; by Sir John Pringle in the health of the Army and public hygiene. In our own day we have been the witnesses of the labours of a group of physiologists, who have abundantly proved the validity of the constant internal environment by the new light which they have thrown upon the internal secretions, chemical and nervous regulation, and the nutrition of the body of man. They established not only our knowledge as to the basis of the conservation of health, but also the application of that knowledge to the direct prevention of disease. For the unfortunate people suffering from cretinism, goitre, diabetes, anaemia, malnutrition, deficiency disease, beriberi, osteomalacia, scurvy, and rickets-all the world over and for all races-there has been found, within our life time, the answer to their malady, the repair of the disturbance of balance in their constant internal environment, and the means by which such disturbance may be avoided in future. In a word, we now know that physical health and mental capacity depend upon a mutual contribution of nutrition, hormones, nervous regulation, and oxygenation of the circulating blood, as we also know how these factors can be made direct instruments of the prevention of disease, and thus fulfil the office of medicine, " to tune this curious harp of man's body and reduce it to harmony."

\section{The Cause and Control of Infective Disease}

As a second example of the Harveian method and spirit at work we may take the study of the cause and control of infective diseases. As we have seen, Harvey himself held that the circulating blood carried infection. No group of men followed more faithfully the teaching of Harvey and Sydenham than the physicians of the eighteenth century. By that time the circulation of the blood was fully accepted and Harvey's mode of workmanship had become part of English tradition. What was lacking was any exact knowledge of causation. In spite of that, the practical sense of the English did, in fact, achieve before the end of the eighteenth century, two significant conquests in this long list of diseases-namely, the control of scurvy and of small-pox.

The mighty movement which changed the whole situation was the advance of bacteriology. It began with surmises and conjectures in the sixteenth century. But, as we all know, it was Louis Pasteur and Robert Koch who eventually proved the case ; Pasteur by his study of fermentation and viruses, and Koch by his ingenious technical methods of isolation. Only as we view at a distance their labours in the last half of the nineteenth century are we able to appreciate the revolution in the science and art of medicine which they achieved. If we reflect on the fact that in the brief period of fifteen years, from 1880 to 1895 , there was discovered the bacterial cause of nine diseases-typhoid fever, tuberculosis, suppuration, glanders, cholera, diphtheria, tetanus, Malta fever, and plague ; and that in the same period there was provided the initial form of protective inoculation against anthrax, rabies, diphtheria, tetanus, cholera, and typhoidwe shall understand the magnitude of the modern conquests of preventive medicine. Much had to be done, much still remains to be perfected, but here we are in an altogether new kingdom, the control by the body of infective processes.

The discovery of causal pathogenic organisms immediately led to finding them in the tissues of the affected person. In typhoid, tuberculosis of the lung, diphtheria, tetanus, and plague there arose forthwith the need for a bacteriological diagnosis as well as a clinical. The physician called in the bacteriologist, and the relation of bacteriology to clinical diagnosis became a subject of lively discussion. It stimulated inquiry into possibilities of destroying the bacilli before they entered the body, into the channels of infection (contact, " carrier," droplet infection, clothing, water, milk, etc.) and their control, into inoculation and vaccination, and into antitoxin treatment. Lord Lister's application of antiseptic principles exerted no doubt a highly beneficial effect upon surgery, but its influence was much wider, for it demonstrated a means of control of almost universal application. Dr. Snow and Dr. Budd showed that the biological examination of water supplies became a practicable test of safety ; Dr. Michael Taylor of Penrith did for milk what they had done for water, and that vehicle of infection also came steadily under control ; Cameron and Thorne were among the first to " incriminate" polluted shellfish of conveying the infection of typhoid, and, like water and milk, oysters, too, came first under suspicion and then under control.

Only a generation has passed since the bacterial cause of disease has been our possession. Yet there has been time to assimilate the new knowledge and correlate it with the old, to recognize that in the production and determination of disease the seed is one factor and the soil another. The study of the interaction between them has been illuminating and profoundly instructive. It has confirmed and even fortified the Hippocratic and Harveian confidence in the nature of man's body. Though we 
cannot as yet assess the degree of control with which this new knowledge empowers mankind, we are not without encouragement provided by the remarkable decline in the incidence and mortality of disease.

\section{Immunity}

A third example is artificial immunity, an acquired defence of the host against harmful influences of bacterial origin, perhaps the greatest single advance in modern Preventive Medicine. It was known before Sydenham's day that an attack of measles or small-pox naturally protected the patient from further attack, and Harvey knew that the blood had protective qualities. But it is only in our own times that explanation of this property has been attempted and found. Pasteur used to say that he received part of his inspiration from Jenner and his empirical experiments in vaccination. Pasteur's chicken cholera vaccine was in fact comparable to variolation, the inoculation of an attenuated variola. Four facts formed the basis of the organized exploration which began in our own time: the natural protection provided by an attack of measles or small-pox, the attenuated virus of Jenner and Pasteur, the bactericidal defences of the blood itself, demonstrated by Lister, and the phagocytosis of Metchnikoff.

We now have at command protective inoculation against a number of diseases-for example, small-pox, anthrax, plague, cholera, typhoid, rabies, and diphtheria by attenuated virus in small-pox and rabies, and by the dead bacillus as immunizing agent in the other conditions. In all these cases the antibodies in the blood do not act alone in antagonizing the toxic invasion; they are aided by accompanying cellular changes in the body itself. In the development of acquired immunity we see, in fact, an intensification of the defensive actions and properties possessed by the body in its natural state, which continue after the antibodies have disappeared from the blood. It is common knowledge that the principles of active immunity have now been directly applied in the treatment of already existing infective disease in the form of autogenous strains of the infecting organism, disintegrated or killed. These act by aiding the local defences of the tissues or stimulating the production of antibodies in the blood. It is indeed a confirmation and fulfilment of the Hippocratic doctrine that health and disease are both in themselves " divine," and the body is itself the healer of disease.

Thus the physician is now active in the preventive aspect of healing; his drugs and remedies are not only prescribed for their preventive propensity, but they are specifically preventive in purpose. . . . They are not all of equal value, and some will be ineffective in insusceptible patients. But the strange thing has happened that we are the witnesses of a new approach to disease, a new birth of Medicine, a treatment which is preventive, undreamed of by Harvey and unavailable in this College two generations ago. We all know the results, some of them dramatic and historic throughout the world, some of them local, prosaic, and obscure, but on the whole profoundly beneficial in the reduction of the incidence and mortality of infective processes.

\section{PREVENTIVE WORK OF THE COLLEGE OF PHYSICIANS}

Such then, in brief, is a narrative of Harvey's discovery and some of the subsequent effects to which it led in the realm of Preventive Medicine, and in which the College of Physicians has played so great a part during its 400 years. It was Bacon who said, in 1605, that " it is order, pursuit, sequence, and interchange of application, which is mighty in Nature." But Linacre himself, the founder of the College, might well have written these words a hundred years earlier. For he was their embodiment, and he it was who brought back the Greek learning from Florence and Padua at the end of the fifteenth century that it might inspire English Medicine. In addition to his translations of Galen, he endowed medical lectureships at Oxford and Cambridge, and as physician to the King he prevailed upon Henry VIII in 1518 to establish the College of Physicians for the purpose of advancing medical education and standardizing the practice of medicine. In Linacre's translations and institutions, in the Utopia of his pupil Sir Thomas More, and in the history of this College we may seek and find the beginnings of preventive action in English medical practice.

Before the days of the existence of the Medical Department of the Privy Council in 1858, the College of Physicians was consulted frequently in regard to the practice of Preventive Medicine and the administration of public health measures by the City of London, the Privy Council, and Parliament. In 1627 it was asked to inspect the Alum Works in Aldgate, and Harvey was a member of the committee appointed to report thereon ; in 1648 the question of baths for public use was raised in 1693 the Lords of the Admiralty requested to be advised by the College on medical treatment of sickness in the Fleet, and subsequently for many years on distillation of water, the ventilation of ships, the victualling of ratings, and the prevention of scurvy and the control of infectious disease in the Navy; influenza called for advice periodically from 1784, and in the same year the supervision of madhouses was placed in the hands of the College by Parliament; and from 1831 onwards the College was consulted frequently in regard to the prevention of cholera in England and of leprosy in the Colonies and Dominions.

It is, however, the internal and designed polity of the College in respect of the pharmacopoeia, the registration of the cause of death, the plague and small-pox, and the practice and investigation of its Fellows, which has necessarily led the College of Physicians to take an historic share.

\section{The Pharmacopoeia}

In the Letters Patent constituting the College in 1518 there was included a provision consigning to four persons named by the College the duty of " the correction and government of physic and its professors (practitioners), together with the examination of all medicines, and the power of punishing offenders by fine and imprisonment." This duty, confirmed by statute in 1522 , was discharged by the College for 340 years, until 1858. It was part of its internal polity, even a reason for its foundation. In 1540 the College was empowered by statute to destroy any defective drugs which their authorized representatives found as a result of their examinations. These College visitors were the forerunners of the inspectors and analysts under the Sale of Food and Drugs Act of 1875 and its successors, and this control and authorization of drugs of recognized standard has been of immense protective and constructive value to the science and practice of medicine.

In 1618 the College produced the first Pharmacopoeia. Subsequently nine editions were published from 1650 to 1851. The Medical Act of 1858 transferred the duty from the College to the General Medical Council.

For the first 170 years these pharmacopoeias followed the traditional custom derived from the Arabians, being an inventory of drugs used and approved for the time being. But the additions became both more scientific and more directional in 1788 and 1836 . The Pharmacopoeia of 1836 is marked by the admission to its pages for the first time of the alkaloids, aconite, quinine, morphine, strychnine, hydrocyanic and phosphoric acids, iodine and bromine preparations, creosote, ergot, and lobelia. Thus was introduced into practical pharmacology in England that new philosophy of the art of therapeutics which is designed to control the internal forces which affect the 
body or its organs injuriously by means of counteraction, neutralization, or prophylaxis.

Since the General Medical Council took over from the College, under statute, the duty of authorizing a pharmacopoeia they have produced six British Pharmacopoeias from 1864 to 1932 . If the latest and current edition be compared with the Pharmacopoeia of 1836 it will be observed that inter alia it is characterized by two new features. There has been a substantial increase in the number of authorized prophylactic drugs, such as cod. liver oil, liver extract, salvarsan, sanocrysin, atropine, and glucose ; and it contains for the first time a new category of biological agents of a directly preventive nature, the use of which has greatly strengthened what the compilers of the reformed Pharmacopoeia of 1836 called "the armamentarium of the physician," particularly in respect of artificial immunity. For among these biological substances are the vaccines, antitoxins, and antibacterial serums, thyroid and parathyroid extract, insulin, adrenaline, and pituitrin, now standardized under the Therapeutic Substances Act of 1925.

\section{Registration of Cause of Death and Nomenclature} of Disease

There is a second example of the policy of the College to which brief reference should be made, and which has had still more far-reaching preventive effects. The year before Queen Victoria came to the throne Parliament passed an Act for the registration of births and deaths, a natural corollary to the Census of 1801 . Births and deaths had been partially registered in the parish records of England since the days of Queen Elizabeth. But many of these church registers having been lost, the Act of 1836 was passed to make the record secular and complete, independent of religious opinion. Thus did the legislature of England, in the words of Dr. William Farr, "take the lead in advancing the health of Europe." But it was not the Act of 1836 which secured this, for it alone was insufficient. In the spring of 1837 the Registrar-General (Mr. Lister) wrote to the College of Physicians soliciting the aid of " every practising member of any branch of the medical profession " in sending to the local registrar of deaths " a written statement of the cause of death" of any person upon whom he was in attendance.

On May 1st Sir Henry Halford, the President, jointly with the President of the College of Surgeons (Sir Astley Cooper) and the Master of the Apothecaries (Dr. Hingeston), issued their memorable circular to the profession asking all practising medical men to enter on the death certificate the authentic cause of death. They claimed that the important object of such returns, when collated, would be more accurate knowledge (1) of the comparative prevalence of various mortal diseases in England and Wales; (2) the localities where they prevailed ; and (3) the age, sex, and condition of life principally affected. Here, then, was a statistical method which, as Farr pointed out in his report to the RegistrarGeneral in 1839, gave the State for the first time the necessary foundation for modern nosology and epidemiology, for treatment and for prevention.

" Any improvement in the treatment of disease," he said, " and any addition to medical science, will tend ultimately to the diminution of human suffering. But the registration of the causes of death is calculated to exercise a still more direct influence upon the public health. Diseases are more easily prevented than cured, and the first step to their prevention is the discovery of their exciting causes."

For the voluntary practice thus initiated by the College the Registrar-General officially and publicly thanked the medical profession, and after a generation of experience Parliament, in 1874, made statutory provision requiring the medical certification of the cause of death in all cases. It is this registration of the cause of death by the medical practitioner which lies at the back of the application and direction to-day of public health measures for communal health

When at the Registrar-General's request Farr undertook the task of classifying the causes of death returned by the medical profession in 1837, he was faced with the immediate necessity of an appropriate nosology. The
College appointed a committee in 1857 , and by 1869 the new Nomenclature of Diseases was ready. On March 6th Her Majesty's Treasury approved of its gratuitous distribution among 20,000 registered practitioners in the United Kingdom.

Statistical data and uniformity of nomenclature are great things, but accurate diagnosis and the correct certification of the cause of death are greater. For this is the first and most fundamental factor in any scientific form of control. It was largely because of this public-spirited contribution by the College of Physicians that the Registrar-General's reports became the basis of the application of Preventive Medicine in England and in civilized States throughout the world.

\section{The Plague}

The contribution of the College to Preventive Medicine was, however, even more direct than its polity. The plague was prevalent in England from 1348 to 1666. From the experience of Wolsey and letters from Erasmus and Sir Thomas More, we know that when the College was founded by Henry VIII there was prevalent in London the third outbreak of the sweat and the plague (which prevented the King from coming to London). In 1518 the King himself, on the advice of his physicians, had recommended the marking of plague-infected houses and preparatory arrangements for quarantine, a recommendation which became the first plague order in 1543 . In 1529 the King urgently consulted his College of Physicians as to what means they advised for the prevention of this disease. The Privy Council in 1532 also on their advice ordered the issue of plague bills, the first of a long series, which were succeeded by the registration of plague deaths in parishes (1539). In 1563 the College was satisfied that there was some relation between animals and human plague, and recommended the destruction of dogs and cats.

From 1630 to 1665 the College of Physicians issued advices periodically as to the prevention of plague. It is true that many of their recommendations were derived from former practices of somewhat mediaeval character, such as the sovereign remedy of flight, the marking of infected houses and persons, the appointment of " searchers," strong-smelling fumigations, and the necessity of sanitary cleanliness. The control of animals and tainted food, the removal of " annoyances," and the speedy burial of the dead emerged from current belief that they served as sources of infection. The medical profession were by no means unanimous as to the best course to take, and Fellows of the College were not always then, as now, in complete agreement with one another.

Richard Mead did not live in the time of the plague, but owing to public alarm as to possible invasion in 1720 , he was, whilst censor of the College, commissioned by the lords of the Regency to advise the Government, and in his Discourse on the Plague he summarized the medical knowledge of his age. He restricted the source of its contagion to infected persons, materials, and air, and his recommendations for defence have a modern touch. There was to be appointed a Council of Health entrusted with requisite powers, and responsible for ascertainment of cases and deaths by competent registrars, isolation of cases, destruction of infected goods, and disinfection of bedding and clothing. More general measures were also to receive official attention, such as sanitation, suppression of vagrancy, sanitary cordons around infected districts, and quarantine. Although the plague never again invaded England, these eighteenth century recommendations have proved the ancestors of modern methods in Europe and the East.

\section{Excessive Spirit Drinking}

A fourth example of the preventive action of the College was singular and significant. In the first half of the eighteenth century $(1730-49)$ the number of deaths of children under 5 was $\mathbf{7 4}$ per cent. of the births, and this was attributed to the orgy of spirit-drinking which characterized the English people in that period, for reasons which we cannot discuss now. Smollett, Cadogan, Willan, and other physicians drew attention to the indisputable evil physical results of this excess. The results were so 
disastrous that in 1725 , during the presidency of Sir Hans Sloane, the College of Physicians petitioned Parliament on this subject.

As a result of this and similar petitions and appeals Parliament passed the Gin Acts of 1736, 1751, and 1752, for the suppression of gin-shops and the restriction of private retail sales. One hundred and ninety years later a somewhat similar social problem faced the nation, and the Government appointed the Liquor Control Board (1915-18). The effect of that Board's administration in securing a sober people is well known to us all.

\section{Small-pox and Vaccination}

My last illustration may be vaccination. Inoculation of diminutive doses of small-pox serum for the prevention of natural small-pox was introduced into England by Timoni, a Greek of Constantinople, in 1713, and was practised tentatively until 1798, when Jenner announced his method of vaccination with the serum of cow-pox as a means of protecting the human constitution from the infection of small-pox. This was substituted for the method of small-pox inoculation. Jenner also kegan forthwith the organization of communal vaccination. Subsequently Parliament prayed the King to "direct His Royal College of Physicians to inquire into the state of the vaccine inoculation in the United Kingdom, and to report their opinion as to the progress which it has made, and the causes which have retarded its general adoption." The College replied in 1807, and their memorable answer, signed by Sir Lucas Pepys, was the beginning of their leadership in small-pox prevention. Following on this declaration by the College there was a debate in the House of Commons on June 9th, 1808, in which Mr. Rose secured the assent of the House to a resolution, " that public benefit would be derived from the establishment of a central institution in London for the purpose of rendering vaccinia inoculation generally beneficial to His Majesty's subjects." On this resolution the Privy Council called upon the College of Physicians to appoint a Medical Board to inquire into the methods of vaccination generally used, with their success or failure, and to organize and set in action a central institution in Leicester Square for carrying on in London, under their own immediate superintendence, the practice of vaccination, and for distributing vaccine lymph to every part of the Empire. This Board continued until 1860.

Thus, for more than fifty years, the College of Physicians became the pronounced advocate of vaccination, undertook to initiate the control of the national movement for vaccination, inquired into its results, supervised its working, and standardized and distributed the lymph. Subsequently these duties were undertaken by the Privy Council from 1861 to 1871 , by the Local Government Board from 1871 to 1919 , and since that date by the Ministry of Health. Closely allied to this remarkable service of the College was their action a generation later in respect of antitoxin for diphtheria.

In 1890 the Conjoint Board of the two Colleges rendered powerful aid to the administrative and educational aspects of communal Preventive Medicine by creating a special Diploma in Public Health (under the Medical Act of 1886), followed subsequently by a comparable Diploma in Tropical Medicine and Hygiene.

\section{CONCLUSION}

Throughout its history the College of Physicians has been the foster-mother of sound medical practice, and in each of its four centuries has nurtured and cultivated the Renaissance spirit of true learning and inquiry. From its earliest years it has had many Fellows or Licentiates who have contributed to the advancement of the science and art of Medicine, and not a few who have moved forward our knowledge in Physiology and Pathology and their applications to Preventive Medicine. Named or unnamed, these are the workers whom we commemorate to-day, and whose works do follow them.

But their works follow them in a new world. The extraordinary advance in the science and art of medicine has supplemented the work of the family physician of a former day by providing an extensive system of general and special hospitals, laboratories, sanatoriums, and clinics, with a no less comprehensive system of specialists on the one hand and public medical services on the other. Yet the family physician will always remain the most economic and effective physician for the vast majority of human ailments. In any event the registered medical practitioner will be the first into whose hands will fall the recognition and treatment of the beginnings of disease. Moreover, the practice of medicine must always remain both inductive and individualistic.

There is evidence that the State appointed public doctors at least as early as Democedes (c. 510 в.c.), and the custom was extensively followed throughout the Roman Empire. In England the first obvious intervention by the State was in the sixteenth century on account of the existence of certain foci of disease among the poorest and most vagrant class of the community, neither able nor willing to obtain medical advice and yet contributing to the spread of disease in the community. It became apparent that the State was the only available authority which could direct the application of advancing medical knowledge and practice to the problem. In the first half of the nineteenth century such action of the State became more formal and statutory, both in providing medical and surgical treatment for the poorest classes and in formulating sanitary measures to protect the whole community against insanitary environment or the spread of infectious disease.

This profound and far-reaching development of a communal medical service has proceeded alongside the work of private practice. Since 1834 there has been a Poor Law medical service, and out of it a few years later emerged the Public Health Service, which in recent times has incorporated a number of special medical services, including those for maternity and child welfare, for the schrool child, and for health insurance, each of which had begun in a voluntary form and grown spontaneous!y before the State had recognized its validity. No single person and no single movement is responsible for this creation or its development; it has emerged as part of the social evolution of the time in which we happen to live. Speaking generally, however, it is expedient that certain principles should be recognized in any public medical service.

(a) The province of the State should be to bring the physician and the patient together under circumstances which will be acceptable to the patient, whilst facilitating and safeguarding the work of the physician;

(b) the State should encourage the provision of the necessary hospitals and clinics with proper equipment;

(c) no one, not even the State, should come between the physician and his patient, whether in private or in public practice. For the physician (and not the agency, whether voluntary or statutory, which brings his patient) must both diagnose the morbid condition and prescribe effective treatment;

(d) the State should exercise supervisory administrative control if the medical service in which the physician is engaged is communal or is paid for, partly or wholly, by rates or taxes.

There is nothing here which in principle departs from the primary and paramount benefit of the patient, or invades the reasonable prerogatives of the physician. Indeed, in the English health insurance system there is free choice of physician and patient; advice, treatment, and prevention within the compass of the knowledge and experience of the private practitioner; and the maintenance of the responsibility of the patient, through his contributions, for the payment of the practitioner. Moreover, the system is such that it imposes a check on excessive 
claims of patients and on protracted benefit received during incapacity; in administration it is free from political control, for the management is in the hands of the contributor and the physician, as well as statutory bodies and the State; it provides for the education of the people in hygiene by their own physicians; and, lastly, it is so designed as to provide facilities for the initiation of research, and the keeping of fuller clinical records than in the past.

Such a system cannot insure, or indeed be ultimately effective, any more than private practice can be ultimately effective, unless the principles of preventive action in regard to the processes of disease in the individual are recognized and practised.

It is obvious that numerous problems lie in front of the development of the co-operative association of the private practice of a former time with the pub!ic medical services of a new epoch. One thing is clearly necessary and even predominant-namely, mutual co-ordination between all channels and means of medical activity, in order that the integrity and good will of the healing art may be maintained, and that the patient, be he rich or poor, may receive the full advantages of the science and art of Medicine which have become available since the days of Harvey's demonstration of the circulation of the blood.

\section{GENITAL PROLAPSE: OBSERVATIONS ON ITS DIAGNOSIS, MECHANISM, AND TREATMENT *}

\author{
BY THE LATE
}

H. LEITH MURRAY, M.D., F.C.O.G.

PROFESSOR OF OBSTETRICS AND GYNAECOLOGY, LNIVERSITY OF L.IVERPOOL

As Chaucer said of predestination, "Of it is great deputision, and hath been, of a hundred thousand men." He might have written so of prolapse in this year of grace.

\section{Diagnosis of Prolapse}

In considering the case of a parous woman who complains of pain in the back and is found on examination to have a lax vagina, it is easy to decide that the two features are associated, and one can very often prove that there is a relationship. But in many cases there is no association whatsoever. Many conditions other than prolapse have been sent to me in recent years with an intimation that operation for, or other treatment of, a prolapsing pelvic floor was considered advisable; each one of them had already been under treatment on that diagnosis, usually by a pessary. The following is a list of these conditions: cystitis, fibroids, ovarian cysts or solid tumours, urethral caruncle, visceroptosis, rheumatoid conditions of the lower lumbar spines, fibrositis of the lumbar muscles, spinal caries, root pain due to spinal tumour, scoliosis, sacro-iliac disease of one kind or another, spondylitis deformans, carcinoma of the cervix, constipation, and anal fissure. If ailments so varied can lead to a diagnosis of genital prolapse, surely there must be some lack of appreciation of the essential symptoms and features of that condition? I shall attempt to explain why these mistakes of diagnosis continue to occur, and in what directions subtler investigation would lead to more accurate diagnosis.

\section{Symptoms and Signs}

Any parous woman can have her vagina more lax than the average. Many women have " a pain in the back." But it is of paramount importance to appreciate the

* Based on a paper read to the North Wales Branch of the British Medical Association. relation, or lack of relation, between this very common sign and this very common symptom. If $I$ had to express in a few words one of the very essential features of prolapse, so far as diagnosis is concerned, I would put it as follows: the symptoms bear less relation to the degree of prolapse than to the rate of development. Two cases very similar at examination may present great differences in their symptoms. Prolapse has some features in common with flat-foot. While the condition is progressive there will be symptoms, but if the condition be stationary no symptoms need arise. The medical man, therefore, who examines a case presenting some suggestion of prolapse may readily be led astray by an observed laxity of the vagina. He has to decide, so far as he can, whether this laxity is merely due to multiparity, a descent without symptoms (that is to say, more or less stationary), or a descent that is in process of development.

One of the marvels of child-bearing lies in the amazing degree to which the pelvic floor can be dilated by a large-headed baby with a subsequent degree of involution which maintains the pelvic floor intact so far as symptoms are concerned. I think I have reasonable evidence that the popular idea of a further delivery being able to cure mild degrees of prolapse is not without some foundation. The question in such cases is really whether a subinvolution of the vagina and its adjacent supports, "as the result of one delivery, can be overcome during convalescence from a subsequent labour. Those of us who operate have the clearest evidence, in many cases, that subinvolution of the pelvic floor as a whole, without marked injury, is an important factor in genital prolapse. If the vagina can be easily, mobilized by gauze pressure, surely serious tearing can have been no important feature of the descent. It is wrong to consider subinvolution as a condition limited to the uterus. I would like to see more appreciation of the occurrence of a diffuse subinvolution of the whole pelvic floor. If this be admitted, the possibility of enhapced restitution as the result of a later confinement can only with difficulty be denied. Conversely, it is almost equally surprising to observe the amount of injury that can be inflicted on the genital passages by the rapid descent of a small and premature baby. One cannot, therefore, judge of maternal injury by looking at the newborn child. Still less can one judge it by the time taken to deliver a full-term child, provided that the duration of labour lies within reasonable limits. Further -and here $I$ am afraid $I$ am rather heterodox-it is a difficult matter in many cases to assign responsibility for symptoms of descent arising subsequent to the application of forceps. Nothing is further from my intention than to save the face of those who apply forceps unjustifiably. It may well be true that a high percentage of genital injury is due to an injudicious application. The indications for the application of forceps are clear and agreed ; regrettably often they are not obeyed. This subject, however, is scarcely germane to my present thesis.

Some of the worst cases of prolapse I have ever seen were attended by midwives alone and showed no particular evidence of injury. On the other hand, I have seen the cervix outside the vulva in a newly born infant and in nulliparous women from adolescence to the sixties. Nulliparous prolapse certainly cannot be limited to those very aggravated cases where there is protrusion: the varying age incidence seems to prove that. A case in the sixties with the cervix beginning to protrude at the vulva must have had prolapse in progress for some timeprobably for many years. There must surely be many cases of potential, or slight, nulliparous prolapse which, under the easiest possible circumstances of delivery, tend to become aggravated by that event. Tearing of the perineum per se is a negligible factor in prolapse. Some degree of abnormality higher up, be it more or less gross 